\title{
China county-based demographics, clinical characteristics, treatment patterns, and health resource consumption analysis for diabetes
}

\author{
Wenhua Mao ${ }^{1}$, Xiaoju Qi ${ }^{2}$, Yanfei Huang ${ }^{3}$, Dongmei Yang ${ }^{4}$, Chaoyong Wen ${ }^{5}$, Xianrui Xiong ${ }^{2}$, Yao $i^{2}$, \\ Zhenfeng Zhao' ${ }^{2}$ Jianling Huang ${ }^{2}$, Kaifu Luo ${ }^{1}$ \\ ${ }^{1}$ Admin Office, Yun County People's Hospital, Lincang, China; ${ }^{2}$ Department of Endocrinology, Yun County People's Hospital, Lincang, China; \\ ${ }^{3}$ Department of Nephrology, Yun County People's Hospital, Lincang, China; ${ }^{4}$ Department of Cardiology, Yun County People's Hospital, Lincang, \\ China; ${ }^{5}$ Department of Ophthalmology, Yun County People's Hospital, Lincang, China \\ Contributions: (I) Conception and design: K Luo, W Mao; (II) Administrative support: K Luo, W Mao; (III) Provision of study materials or patients: \\ X Qi, Y Huang, D Yang, C Wen, X Xiong, Y Li, Z Zhao, J Huang; (IV) Collection and assembly of data: All authors; (V) Data analysis and \\ interpretation: X Qi, Y Huang, D Yang, C Wen, X Xiong, Y Li, Z Zhao, J Huang; (VI) Manuscript writing: All authors; (VII) Final approval of \\ manuscript: All authors. \\ Correspondence to: Kaifu Luo. Admin Office, Yun County People’s Hospital, Lincang, China. Email: yxrmyy160@163.com.
}

Backgroundk The diagnosis and treatment of diabetes depends on reasonable chronic disease management. Compared with urban areas, county areas are high-risk areas for chronic disease patients, due to the low awareness of chronic disease, poor treatment compliance with chronic disease, low drug persistence, and low cure rate. Therefore, more attention should be paid to chronic disease management in county areas.

Methods: This retrospective, observational study was conducted at the Yun county medical community, Yun county, Yunan province. Data were collected from the medical records of diabetic patients from July 2017 to Aug 2020. The primary outcome variable was the proportion of patients with diabetic complications in county areas. The secondary outcome variables were demographics and clinical characteristics of diabetic patients in county areas, achievement of the $\mathrm{HbA}_{1 \mathrm{c}}$ target, and clinical inertia of diabetic patients in county areas. Comparisons of the simple diabetes group and the diabetic kidney disease (DKD) group in terms of demographics, clinical characteristics, treatment patterns, and health resource consumption were also conducted. A series of appropriate statistical tests were applied to the study population to examine the various outcomes.

Results: A total of 9,721 type 2 diabetic patients were included for the study analysis. Diabetic retinopathy (11.83\%), cerebrovascular disease (10.31\%), and DKD (9.29\%) were the 3 most common complications in overall admissions. Among the 1,347 patients with HbA1c test results, $536(39.8 \%)$ patients achieved the $\mathrm{HbA}_{1 \mathrm{c}}$ target, while $566(87.62 \%)$ of the 661 patients who did not achieve the $\mathrm{HbA}_{1 \mathrm{c}}$ target had clinical inertia during the next 6 months. Compared with simple diabetes patients, patients with DKD had a higher age, wider coverage of medical insurance, and longer duration of diabetes, and were more likely to be complicated with hyperuricemia, dyslipidemia, and hypertension. Regular insulin, metformin, alphaglucosidase inhibitor, and sulfonylurea were the most widely used antidiabetic drugs in patients with DKD. The health resources consumption also significantly increased.

Conclusions: The proportion of complications in diabetic patients is high in county areas, and blood glucose control is still insufficient. Chronic complications are the key reasons for the decrease in quality of life and high medical costs.

Keywords: Diabetes; chronic disease management; treatment patterns; health resource consumption; China county 
Submitted May 25, 2021. Accepted for publication Jun 29, 2021.

doi: 10.21037/apm-21-1591

View this article at: https://dx.doi.org/10.21037/apm-21-1591

\section{Introduction}

According to the International Diabetes Federation (IDF), an estimated 463 million adults aged 20-79 years are currently living with diabetes, and the number of deaths resulting from diabetes and its complications in 2019 was estimated to be 4.2 million (1). Epidemiological studies have shown that in China, the prevalence of diabetes mellitus among adults aged above 18 years is $10.4 \%$ (2). Despite being a non-fatal disease, diabetic patients may suffer a series of chronic complications such as those of the heart, blood vessels, kidneys, retina, and nervous system due to poor blood glucose control (3). In China, about $73.2 \%$ of diabetic patients suffer from chronic complications (4), which increases the consumption of health resources and economic burden. Among all chronic complications caused by diabetes, diabetic kidney disease (DKD) is one of the most important microvascular complications, also the most risk for patients, which was a major cause of end-stage renal disease worldwide (5). DKD can progressively reduce kidney function and patients may eventually require renal replacement therapy. More importantly, the risk of cardiovascular and cerebrovascular diseases, as well as the mortality rate is significantly increased among patients with DKD (6), which imposes a heavy economic burden on patients, families, and society. Once DKD has developed, the pathological changes are usually gradual and cannot be easily reversed (7). Thus, it is of great importance to control blood glucose in diabetic patients at a reasonable level, and recognize and intervene in the related complications of diabetes at an early stage to reduce the medical burden of diabetic patients.

The diagnosis and treatment of diabetes depends on reasonable chronic disease management. Chronic disease management is defined as an organized, proactive, multicomponent, patient-centered approach to healthcare delivery that involves all members of a defined population who have a specific disease entity (or a subpopulation with specific risk factors) (8). Diabetes-related complications develop from diabetes mellitus, and patients' blood glucose and blood pressure control, lifestyle, diet, and other factors are closely related to the progress of the disease. Therefore, chronic disease management methods for patients with diabetes are mainly based on these aspects. With the gradual advancement and improvement of hierarchical diagnosis and treatment in China, the chronic disease management of patients with diabetes and its complications has also been continuously developed.

Although many studies on the current situation of the diagnosis and treatment of diabetes patients had been conducted, the viewpoints of diabetic patients in the county areas remain lacked. Compared with urban areas, county areas are high-risk areas for chronic disease patients, due to the low awareness of chronic disease, poor treatment compliance with chronic disease, low drug persistence, and low cure rate. Therefore, more attention should be paid to chronic disease management in county areas. Understanding the current situation of diabetic patients in county areas would be helpful in rational chronic disease management. Yun county is located in Yunnan province, in the southwest of China, with a permanent population of 460,000 and a total population of approximately 700,000. According to a recent population survey, the prevalence of diabetes in Yunnan province is $12.6 \%$ in 2017, which means a large population of diabetic patients existed in Yun county (9). As a representative county area, Yun county has faced the same situation of low awareness rates and poor treatment compliance in chronic disease management. From June 2014, Yun county has started the construction of a county medical and health community centered on the close-knit integrated management of county and rural medical and health services. The superior hospitals, Yun county people's hospital and Yun county traditional Chinese medicine hospital, cooperated with 13 subordinate hospitals of township health centers to optimize and integrate resources, providing the supply of basic health services covering the whole jurisdictions within the county, including villages, townships and the towns, and promoting the implementation of hierarchical diagnosis and treatment (10). Since 2017, the Yun county medical community has gradually established the Yun county medical community health information platform. All hospitals in the community use the same electronic information system to realize the standardization of medical records, medical orders, and medical reports.

Primary medical service institutions are the main facilitators of chronic disease management in the 
hierarchical diagnosis and treatment mode. In order to improve the chronic disease management ability of primary medical service institutions and improve life expectancy, the Yun county medical community promotes the construction of a primary chronic disease management center. Since 2018, the Yun county medical community health information platform has gradually completed the collection of medical information and expense information of all patients in village clinics, township hospitals, and county hospitals. Therefore, this study intends to investigate the clinical status and disease burden of patients with diabetes in Yun county, in order to understand the current situation of chronic disease management of patients with diabetes at the county level in China, and finally provide evidence for the early diagnosis and treatment of diabetic complications. We present the following article in accordance with the STROBE reporting checklist (available at https://dx.doi. org/10.21037/apm-21-1591).

\section{Methods}

\section{Study design and data collection}

This retrospective, observational study was conducted at Yun county medical community, Yun county, Yunan province, and approved by the Institutional Review Board of Yun county people's hospital (approval number: 202103). All procedures performed in this study involving human participants were in accordance with the Declaration of Helsinki (as revised in 2013). Individual consent for this retrospective analysis was waived. The study research period was designed according to the actual time process of the construction of the Yun county medical community health information platform. Data were collected from the medical records of diabetic patients from July 2017 to Aug 2020. The medical data included information related to demographics, diagnosis, prescription patterns, laboratory examinations, procedures, and detailed medical expenses. Based on the objective of the study, patients admitted to the hospital with at least one visit of "diabetes mellitus" diagnosis during the time period of July 2017 to Aug 2020 were included. Patients were excluded if they were diagnosed with "type 1 diabetes mellitus" or "gestational diabetes mellitus" during the time period of Jul 2017 to Aug 2020. Among all diabetic patients finally included, diabetic patients who had no visit with a diagnosis of diabetic complications during the study period were categorized as the simple diabetes group. Diabetic patients who had at least one visit with a diagnosis of DKD during the study period, diabetic patients who had at least one laboratory test result of estimated glomerular filtration rate (eGFR) $<60 \mathrm{~mL} \cdot \mathrm{min}^{-1} \cdot\left(1.73 \mathrm{~m}^{2}\right)^{-1}$ during the study period, or diabetic patients who had at least two laboratory test results of urinary albumin creatinine ratio (UACR) $\geq 30 \mathrm{mg} / \mathrm{g}$ during 6 months in the study period were categorized as the DKD group.

\section{Study variables}

The primary outcome variable was the proportion of patients with diabetic complications in county areas. The secondary outcome variables were demographics and clinical characteristics of diabetic patients in county areas, achievement of the $\mathrm{HbA}_{1 \mathrm{c}}$ target, and clinical inertia of diabetic patients in county areas. Achievement of the $\mathrm{HbA}_{1 c}$ target was defined as the laboratory result of $\mathrm{HbA}_{1 \mathrm{c}}$ level $<7 \%$, and clinical inertia was defined as diabetic patients with $\mathrm{HbA}_{1 \mathrm{c}}$ level $\geq 7 \%$ but who did not have any added oral hypoglycemic agents or initiated insulin therapy during the next 6 months.

Furthermore, in the comparison of the simple diabetes group and the DKD group, the outcome variables included demographics, clinical characteristics, treatment patterns, medical resources, and disease economic burden.

\section{Statistical analysis}

In this study, quantitative data were analyzed using number of patients (n), mean, standard deviation (SD), minimum (min), maximum (max), median (MED), upper quartile (Q1), and lower quartile $(\mathrm{Q} 3)$. The $t$-test was used in the case of normally distributed data and the Wilcoxon rank sum test was used for non-linearly distributed data. Qualitative data were analyzed using frequency tables, percentages, or constituent ratios. When $20 \%$ of the lattice frequency was $<5$, Fisher's exact test was used, and a Chi square test was used for determination of the remaining parameters. All analysis was conducted with statistical analysis software $\mathrm{R}$ (version 3.5).

\section{Results}

Demographics and baseline characteristics of patients with type 2 diabetes

A total of 9,721 type 2 diabetic patients were included 
Table 1 Baseline demographics and clinical characteristics of the overall diabetic population

\begin{tabular}{|c|c|}
\hline Characteristics & Overall $(n=9,721)$ \\
\hline Age (years) & $55.63 \pm 12.75$ \\
\hline Gender (\% male) & 48.56 \\
\hline \multicolumn{2}{|l|}{ Insurance status (n, \%) } \\
\hline Insured & $8,193(84.28)$ \\
\hline Self-paid & $1,167(12.00)$ \\
\hline Unknown & $361(3.71)$ \\
\hline \multicolumn{2}{|l|}{ Nationality, n (\%) } \\
\hline Han & $8,956(92.13)$ \\
\hline Yi & $320(3.29)$ \\
\hline Blang & $68(0.70)$ \\
\hline Hui & $41(0.42)$ \\
\hline Bai & $38(0.39)$ \\
\hline Dai & $19(0.20)$ \\
\hline Lahu & $9(0.09)$ \\
\hline Lisu & $5(0.05)$ \\
\hline Miao & $4(0.04)$ \\
\hline Other & $248(2.55)$ \\
\hline Unknown & $12(0.12)$ \\
\hline $\mathrm{BMI}\left(\mathrm{kg} / \mathrm{m}^{2}\right)$ & $23.88(21.37,26.64)$ \\
\hline Disease duration (years) & $5.06 \pm 3.80$ \\
\hline UACR (mg/g) & $27.21(17.14,54.54)$ \\
\hline eGFR $\left[\mathrm{mL} \cdot \mathrm{min}^{-1} \cdot\left(1.73 \mathrm{~m}^{2}\right)^{-1}\right]$ & $92.07 \pm 38.13$ \\
\hline Uric acid $(\mu \mathrm{mol} / \mathrm{L})$ & $324.50(255.00,405.00)$ \\
\hline TC (mmol/L) & $5.47 \pm 1.95$ \\
\hline LDL (mmol/L) & $2.94 \pm 1.26$ \\
\hline \multicolumn{2}{|l|}{ Medical history, n (\%) } \\
\hline Hypertension & $1,945(20.01)$ \\
\hline Stroke & $527(5.42)$ \\
\hline Hyperlipidemia & $1,716(17.65)$ \\
\hline Tumor & $56(0.58)$ \\
\hline Myocardial infarction & $24(0.25)$ \\
\hline Myocardial ischemia & $24(0.25)$ \\
\hline Transient ischemic attack & $12(0.12)$ \\
\hline Atrial fibrillation & $11(0.11)$ \\
\hline End-stage liver disease & $10(0.10)$ \\
\hline Hyperuricemia & $552(5.68)$ \\
\hline
\end{tabular}

$\mathrm{BMI}$, body mass index; UACR, urinary albumin creatinine ratio; eGFR, estimated glomerular filtration rate; TC, total cholesterol; LDL, low density lipoprotein. for the study analysis. The mean age of the overall population was $55.63 \pm 12.75$ years, with $48.56 \%$ male patients. Approximately $84.28 \%$ of them were insured and $12.00 \%$ were self-paid (Table 1 ). Han nationality was the largest ethnic group (92.13\%). Hypertension (20.01\%), hyperlipidemia (17.65\%), and hyperuricemia (5.68\%) were the 3 most common underlying diseases among the overall diabetic population.

\section{Proportion of complications in patients with type 2 diabetes}

Diabetic retinopathy $(11.83 \%)$, cerebrovascular disease (10.31\%), and DKD (9.29\%) were the 3 most common complications in overall admissions (Table 2). The most common reasons for outpatient admissions were diabetic retinopathy $(11.72 \%)$, cerebrovascular disease $(10.21 \%)$, and DKD $(9.13 \%)$, while for inpatient admissions, the most common complications were DKD (6.17\%), diabetic retinopathy $(6.09 \%)$, and cerebrovascular disease $(5.77 \%)$.

\section{Achievement of the $\mathrm{Hb} A_{1 c}$ target and clinical inertia in patients with type 2 diabetes}

Among all 9,721 patients with type 2 diabetes, only 1,347 patients had $\mathrm{HbA}_{1 \mathrm{c}}$ test results (Table 3), 811 patients with $\mathrm{HbA}_{1 \mathrm{c}}$ measurements of $7 \%$ or greater were screened, while $536(39.8 \%)$ of patients achieved the $\mathrm{HbA}_{1 \mathrm{c}}$ target. Among the 811 patients with type 2 diabetes who failed to achieve the $\mathrm{HbA}_{1 \mathrm{c}}$ target, 646 patients had medication records within 15 days before and after baseline diabetes admission, and 566 of them did not add any oral hypoglycemic agents or initiate insulin therapy within 6 months after baseline diabetes admission. The calculated incidence of clinical inertia was $87.62 \%$.

\section{Clinical characteristics, treatment patterns, and bealth resources consumption of patients with DKD}

A total of 6,002 simple diabetes patients and $730 \mathrm{DKD}$ patients were finally enrolled in this part of the study (Table 4). The mean age, insurance coverage, and disease duration in the DKD group were significantly higher than in the simple diabetes group, while the BMI was significantly higher in the simple diabetes group. Compared to the simple diabetes group, patients in the DKD group were more likely to have hypertension, stroke, hyperlipidemia, tumor, myocardial ischemia, end-stage liver 
Table 2 Proportions of diabetic complications among patients with type 2 diabetes in county areas

\begin{tabular}{lccc}
\hline Complications & Outpatient $(\mathrm{n}=9,611), \mathrm{n}(\%)$ & Inpatient $(\mathrm{n}=3,254), \mathrm{n}(\%)$ & Overall $(\mathrm{n}=9,721), \mathrm{n}(\%)$ \\
\hline With at least one complication & $3,797(39.51)$ & $2,025(62.23)$ & $3,858(39.69)$ \\
Diabetic kidney disease & $888(9.24)$ & $600(18.44)$ & $903(9.29)$ \\
Diabetic retinopathy & $1,139(11.85)$ & $592(18.19)$ & $1,150(11.83)$ \\
Cerebrovascular disease & $993(10.33)$ & $561(17.24)$ & $1,002(10.31)$ \\
Diabetic neuropathy & $582(6.06)$ & $461(14.17)$ & $597(6.14)$ \\
Cardiovascular disease & $550(5.72)$ & $382(11.74)$ & $553(5.69)$ \\
Diabetic peripheral vasculopathy & $380(3.95)$ & $316(9.71)$ & $391(4.02)$ \\
Diabetic ketoacidosis & $205(2.13)$ & $176(5.41)$ & $217(2.23)$ \\
Diabetic foot & $119(1.24)$ & $63(1.94)$ & $123(1.27)$ \\
Hyperglycemic hyperosmolar state & $23(0.24)$ & $15(0.46)$ & $25(0.26)$ \\
Diabetic lacatocidosis & $5(0.05)$ & $4(0.12)$ & $6(0.06)$ \\
\hline
\end{tabular}

Table 3 Proportion of achievement of the $\mathrm{HbA}_{1 \mathrm{c}}$ target and clinical inertia among patients with type 2 diabetes in county areas

\begin{tabular}{lc}
\hline Blood glucose control & Number of patients, $\mathrm{n}(\%)$ \\
\hline With $\mathrm{HbA}_{1 \mathrm{c}}$ test results $(\mathrm{N}=9,721)$ & $1,374(14.13 \%)$ \\
Achievement of the $\mathrm{HbA}_{1 \mathrm{c}}$ target $(\mathrm{N}=1,374)$ & $536(39.80 \%)$ \\
Clinical inertia $(\mathrm{N}=646)$ & $566(87.62 \%)$
\end{tabular}

disease, transient ischemic attack, and hyperuricemia.

White cell count, serum creatinine (Scr), blood urea nitrogen (BUN), uric acid, and aspartate transaminase (AST) were significantly higher in the DKD group, while hemoglobin, red cell count, platelet count, $\mathrm{HbA}_{1 \mathrm{c}}$, total cholesterol, low density lipoprotein, high density lipoprotein, triglyceride, albumin, and alanine transaminase (ALT) were significantly higher in the simple diabetes group.

Patients with simple diabetes were more likely to choose sulfonylureas, metformin, and alpha-glucosidase inhibitor, and less likely to choose dipetidyl peptidase IV inhibitor (DPP-4), glucagon-like peptide-1 receptor agonist (GLP1 RA), and intermediate-acting insulin (Table 5). However, patients with DKD were more likely to choose regular insulin, metformin, and alpha-glucosidase inhibitor, and less likely to choose DPP-4, GLP-1 RA, and intermediateacting insulin. Furthermore, the use of angiotensinconverting enzyme inhibitors (ACEIs) and angiotensin receptor blockers (ARBs) among DKD patients was lacking.

The annual total visits, annual outpatient visits, and annual inpatient visits of DKD patients were significantly higher than the simple diabetes patients (Table 6), and the medical costs of DKD patients were also significantly higher than the simple diabetes patients.

\section{Discussion}

In this study, we investigated the clinical characteristics and complications of type 2 diabetes patients in the county, and discussed the deficiency of blood glucose control of chronic diabetes management in the county. Furthermore, we evaluated the clinical characteristics, treatment patterns, and disease burden of diabetic patients complicated with $\mathrm{DKD}$ in the county.

With the construction of the health information platform which integrates the medical information from all medical institutions within the county jurisdiction, we could take a thorough look at the real situation of diabetic patients in county areas. Among the 9,721 type 2 diabetic patients who had at least one admission in the county medical community during a total of nearly 3 years, the average age was 55.63 
Table 4 Baseline demographics and clinical characteristics among simple diabetes and diabetic kidney disease patients

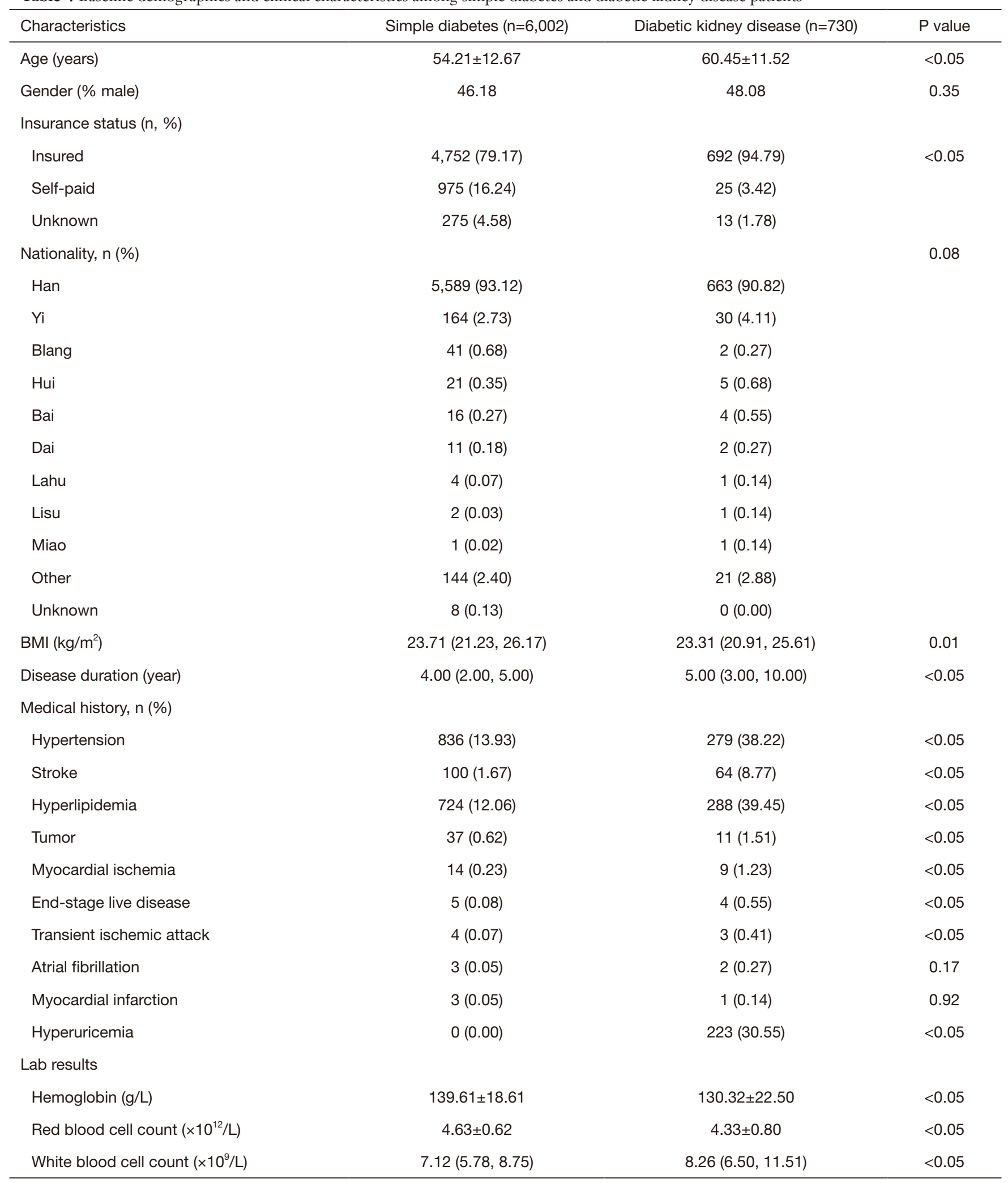

Table 4 (continued) 
Table 4 (continued)

\begin{tabular}{|c|c|c|c|}
\hline Characteristics & Simple diabetes $(n=6,002)$ & Diabetic kidney disease $(n=730)$ & $P$ value \\
\hline Fasting blood glucose (mmol/L) & $9.72(7.33,13.91)$ & $9.22(6.96,13.52)$ & 0.10 \\
\hline $\mathrm{HbA}_{1 \mathrm{c}}(\%)$ & $8.59(6.76,10.60)$ & $8.05(6.36,10.21)$ & $<0.05$ \\
\hline $\mathrm{TC}(\mathrm{mmol} / \mathrm{L})$ & $5.45(4.58,6.33)$ & $4.99(3.98,6.07)$ & $<0.05$ \\
\hline $\mathrm{HDL}(\mathrm{mmol} / \mathrm{L})$ & $1.20(0.99,1.43)$ & $1.13(0.94,1.37)$ & $<0.05$ \\
\hline $\mathrm{TG}(\mathrm{mmol} / \mathrm{L})$ & $2.13(1.43,3.60)$ & $1.89(1.29,2.98)$ & $<0.05$ \\
\hline $\operatorname{Scr}(\mu \mathrm{mol} / \mathrm{L})$ & $65.94 \pm 18.13$ & $146.58 \pm 117.94$ & $<0.05$ \\
\hline BUN (mmol/L) & $5.15 \pm 1.69$ & $9.26 \pm 4.98$ & $<0.05$ \\
\hline ALT (U/L) & $26.00(19.00,40.00)$ & $25.00(17.00,35.00)$ & $<0.05$ \\
\hline AST (U/L) & $24.00(19.00,32.00)$ & $25.00(20.00,35.00)$ & $<0.05$ \\
\hline eGFR $\left[\mathrm{mL} \cdot \mathrm{min}^{-1} \cdot\left(1.73 \mathrm{~m}^{2}\right)^{-1}\right]$ & $103.36(86.40,125.42)$ & $52.26(39.03,59.35)$ & $<0.05$ \\
\hline UACR (mg/g) & $20.88(12.86,32.05)$ & $155.91(40.69,262.10)$ & $<0.05$ \\
\hline
\end{tabular}

BMI, body mass index; TC, total cholesterol; LDL, low density lipoprotein; HDL, high density lipoprotein; TG, triglyceride; Scr, serum creatinine; BUN, blood urea nitrogen; ALT, alanine transaminase; AST, aspartate transaminase; eGFR, estimated glomerular filtration rate; UACR, urinary albumin creatinine ratio.

years old, most of them had high BMI $(28.15 \pm 46.65)$, and the average course of diabetes was 5.06 years, indicating that an aging population, obesity, and long course of disease commonly existed in the county area, which were higher than reported in previous studies (2). Although 76.61\% of patients with diabetes in this study did not have any other medical history, it should be noted that there were widespread cases of decline in renal function, high uric acid level, and abnormal serum lipid level, which indicates that patients with type 2 diabetes in the county area are usually complicated with other metabolic risk factors. With the increase of blood glucose, blood pressure, blood lipid, and body weight, the risk, development speed, and harm of type 2 diabetes complications will increase significantly $(11,12)$. Thus, the chronic disease management of patients with type 2 diabetes in the county should start with disease education, and improvement of the standardization of diabetes diagnosis and treatment, so as to prevent the process of diabetes.

According to the statistics of admission in the overall diabetic population, the most common complications of diabetic patients in the county area were diabetic retinopathy $(11.83 \%)$, cerebrovascular disease $(10.31 \%)$, $\operatorname{DKD}(9.29 \%)$, diabetic neuropathy $(6.14 \%)$, and cardiovascular disease (5.69\%). Cardiovascular disease, cerebrovascular disease, and DKD are the main causes of disability and mortality in diabetic patients. We observed that the prevalence of DKD, cardiovascular disease, and cerebrovascular disease were lower than other studies conducted in urban areas (DKD, 10.7-34.5\%; cardiovascular disease, $17.1-24.9 \%$; cerebrovascular disease, $6.8-19.2 \%$ ) (13-18). The reasons may refer to missed diagnosis and patient loss due to the poor medical level in county areas. With the continuous development of disease awareness and medical diagnosis technology, it is speculated that the rate of missed diagnosis and patient loss will decrease.

Only $39.8 \%$ of diabetic patients in county areas achieved the $\mathrm{HbA}_{1 \mathrm{c}}$ target. More importantly, $87.62 \%$ of patients who did not achieve the $\mathrm{HbA}_{1 \mathrm{c}}$ target had clinical inertia during the next 6 months. This is lower than the previous national cross-sectional survey, with $49.2 \%$ of patients achieving the $\mathrm{HbA}_{1 \mathrm{c}}$ target (2). If the $\mathrm{HbA}_{1 \mathrm{c}}$ target is not achieved 
Table 5 Treatment patterns among simple diabetes and diabetic kidney disease patients

\begin{tabular}{|c|c|c|}
\hline Species & Simple diabetes $(n=6,002), n(\%)$ & Diabetic kidney disease $(n=730), n(\%)$ \\
\hline ARB & $141(2.35)$ & $102(13.97)$ \\
\hline Sulfonylureas & $1,292(21.53)$ & $187(25.62)$ \\
\hline Meglitinide & $141(2.35)$ & $46(6.30)$ \\
\hline Thiazolidinediones & $99(1.65)$ & $32(4.38)$ \\
\hline Alpha-glucosidase inhibitor & $1,036(17.26)$ & $199(27.26)$ \\
\hline DPP-4 & $0(0.00)$ & $3(0.41)$ \\
\hline SGLT2i & $167(2.78)$ & $36(4.93)$ \\
\hline Regular insulin & $828(13.80)$ & $262(35.89)$ \\
\hline Intermediate-acting insulin & $39(0.65)$ & $14(1.92)$ \\
\hline Long-acting insulin & $412(6.86)$ & $132(18.08)$ \\
\hline Premixed insulin & $525(8.75)$ & $114(15.62)$ \\
\hline
\end{tabular}

ACEI, angiotensin-converting enzyme inhibitor; ARB, angiotensin receptor blocker; DPP-4, dipetidyl peptidase IV inhibitor; SGLT2i, sodium glucose co-transporter 2 inhibitor; GLP-1 RA, glucagon-like peptide-1 receptor agonist.

Table 6 Health resources consumption among simple diabetes and diabetic kidney disease patients

\begin{tabular}{|c|c|c|c|}
\hline Characteristics & Simple diabetes $(n=4,108)$ & Diabetic kidney disease $(n=601)$ & $P$ value \\
\hline Annual outpatient visits & $5.69(2.64,9.02)$ & $8.15(4.00,13.63)$ & $<0.05$ \\
\hline Annual inpatient visits & $2.00(2.00,2.00)$ & $2.00(2.00,4.00)$ & $<0.05$ \\
\hline Average outpatient costs (RMB, $¥)$ & $154.29(74.51,245.33)$ & $165.78(75.45,288.71)$ & $<0.05$ \\
\hline Annual total costs (RMB, $¥)$ & $860.56(340.85,2,342.30)$ & $3,763.33(769.52,10,915.21)$ & $<0.05$ \\
\hline Annual outpatient costs (RMB, $¥)$ & $705.33(307.84,1,603.92)$ & $1,152.63(440.6,2,650.33)$ & $<0.05$ \\
\hline Annual inpatient costs (RMB, $¥)$ & $7,872.03(5,059.25,11,393.83)$ & $11,865.11(5,872.54,22,727.67)$ & $<0.05$ \\
\hline
\end{tabular}

after 3 months, the glucose-lowering regimen should be adjusted (19), and delay in treatment intensification increases the risks of myocardial infarction, heart failure, stroke, and composite venous thrombus embolism in patients with type 2 diabetes (20). Thus, timely adjustment of medication regimen and regular physical examination are the urgent needs of patients with diabetes in county area. Appropriate patient education and informatization of disease management are needed to reach these targets.

Compared with simple diabetes patients, patients with DKD had a higher age, wider coverage of medical insurance, and longer duration of diabetes. Furthermore, patients with DKD were more likely to be complicated with hyperuricemia, dyslipidemia, and hypertension. The average value of eGFR in the DKD group was 53.72, indicating that most patients in the county were in the late stage of renal 
failure. This finding indicates that early diagnosis of DKD in county areas should be taken into account.

Regular insulin, metformin, alpha-glucosidase inhibitor, and sulfonylurea were the most widely used antidiabetic drugs in patients with DKD. According to the guidelines and consensus $(12,21,22)$, for patients with DKD, SGLT2i and GLP-1 RA are recommended to improve renal outcomes, but the rate of SGLT2i and GLP-1 RA use in the DKD group was low. Deficiency of ACEI and ARB use was also observed in the DKD group. It can be suggested that patients with DKD in county areas should increase the use of ACEIs and ARBs, and new types of antidiabetic drugs (SGLT2i and GLP-1 RA) can be selected as appropriate choices for glucose-lowering regimens.

The health resources consumption and medical costs of the DKD group were significantly higher than in the simple diabetes group. The progress of DKD is often irreversible, and most patients eventually develop end-stage renal disease, which is accompanied by a large amount of medical resource depletion and direct medical costs (23).

Diabetes is a major public health problem worldwide, and the occurrence of chronic complications has always been the key reason for the decrease in quality of life and high medical costs. So far, the majority of diabetic studies focus on urban areas, and the real-world data of county areas remain rare. This study performed a thorough investigation into the real-world situation of diabetic patients in the county area, and examined the prevalence of chronic complications and medical costs in Chinese county patients with diabetes. The results of this study can raise the importance of diabetes complications among county police makers, doctors, and patients. At the same time, it provides data support for the development of better disease prevention and management strategies of county areas in the future, so as to reduce the incidence of complications and control the medical costs of diabetes.

This study also has several limitations. First, limited due to the construction process of the health information platform in the county area, we did not have long-term outcome data of diabetic patients. Follow-up management will be carried out with the development of the health information platform. Second, as the diagnosis and evaluation of diabetes and complications depends on thorough laboratory examinations, thus, without regular laboratory examination during the follow-up, the evaluation of diabetes status could not be well described. Due to the county medical level and diagnosis and treatment behavior, there is a lack of laboratory examination results during the follow-up in many diabetes patients, which affected the analysis of the laboratory outcomes.

\section{Conclusions}

The proportion of complications in diabetic patients is high in county areas, and blood glucose control is still insufficient. Chronic complications are the key reasons for the decrease in quality of life and high medical costs. Further reasonable chronic disease management is needed.

\section{Acknowledgments}

Funding: None.

\section{Footnote}

Reporting Checklist: The authors have completed the STROBE reporting checklist. Available at https://dx.doi. org/10.21037/apm-21-1591

Data Sharing Statement: Available at https://dx.doi. org/10.21037/apm-21-1591

Conflicts of Interest: All authors have completed the ICMJE uniform disclosure form (available at https://dx.doi. org/10.21037/apm-21-1591). The authors have no conflicts of interest to declare.

Ethical Statement: The authors are accountable for all aspects of the work in ensuring that questions related to the accuracy or integrity of any part of the work are appropriately investigated and resolved. This study was approved by the ethics committee of Yun County People's Hospital (approval number: 2021-03). All procedures performed in this study involving human participants were in accordance with the Declaration of Helsinki (as revised in 2013). Individual consent for this retrospective analysis was waived.

Open Access Statement: This is an Open Access article distributed in accordance with the Creative Commons Attribution-NonCommercial-NoDerivs 4.0 International License (CC BY-NC-ND 4.0), which permits the noncommercial replication and distribution of the article with the strict proviso that no changes or edits are made and the original work is properly cited (including links to both the formal publication through the relevant DOI and the license). 
See: https://creativecommons.org/licenses/by-nc-nd/4.0/.

\section{References}

1. Federation ID. IDF Diabetes Atlas Ninth Edition. 2019. Available online: https://www.idf.org/e-library/welcome. html. Accessed 1 July 2020.

2. Wang L, Gao P, Zhang M, et al. Prevalence and ethnic pattern of diabetes and prediabetes in China in 2013. JAMA 2017;317:2515-23.

3. Alberti KG, Zimmet PZ. Definition, diagnosis and classification of diabetes mellitus and its complications. Part 1: diagnosis and classification of diabetes mellitus provisional report of a WHO consultation. Diabet Med 1998;15:539-53.

4. Investigation Group of Chronic Complications of Diabetes Society of Chinese Medical Association. Retrospective analysis of chronic complications and related macrovascular diseases in hospitalized patients with diabetes mellitus from 1991 to 2000; 2002.

5. Collins AJ, Foley RN, Herzog C, et al. US Renal Data System 2012 annual data report. Am J Kidney Dis 2013;61:A7, e1-476.

6. Ayodele OE, Alebiosu CO, Salako BL. Diabetic nephropathy--a review of the natural history, burden, risk factors and treatment. J Natl Med Assoc 2004;96:1445.

7. Zitt E, Pscheidt C, Concin H, et al. Anthropometric and metabolic risk factors for ESRD are disease-specific: results from a large population-based cohort study in Austria. PLoS One 2016;11:e0161376.

8. Norris SL, Glasgow RE, Engelgau MM, et al. Chronic disease management. Disease Management Health Outcomes 2003;11:477-88.

9. Li Y, Teng D, Shi X, et al. Prevalence of diabetes recorded in mainland China using 2018 diagnostic criteria from the American Diabetes Association: national cross sectional study. BMJ 2020;369:m997.

10. Luo K. Informatization: to get through the "key path" of medical community. China Health; 2019;11.

11. Gæde P, Lund-Andersen H, Parving HH, et al. Effect of a multifactorial intervention on mortality in type 2 diabetes. N Engl J Med 2008;358:580-91.

12. Garber AJ, Abrahamson MJ, Barzilay JI, et al. Consensus statement by the american association of clinical endocrinologists and American college of endocrinology on the comprehensive type 2 diabetes management algorithm - 2019 executive summary. Endocr Pract 2019;25:69-100.

13. Chinese Diabetes Society; Chinese Medical Association. A nationwide retrospective analysis on chronic diabetic complications and related macrovascular diseases of inpatients with diabetes during 1991-2000. Zhongguo Yi Xue Ke Xue Yuan Xue Bao 2002;24:447-51.

14. Chen X, Tang L, Chen H, et al. Assessing the impact of complications on the costs of type 2 diabetes in urban China. Chin J Diabetes 2003;11:238-41.

15. Liu Z, Fu C, Wang W, et al. Prevalence of chronic complications of type 2 diabetes mellitus in outpatients - a cross-sectional hospital based survey in urban China. Health Qual Life Outcomes 2010;8:62.

16. He $M, Y u X$, Liu $Z$. The impact of diabetic complications on the costs for inpatients with diabetes mellitus. Chin J Diabetes 2014;22:452-4.

17. Wei H, Chen F. Clinical characteristics and related factors of chronic complications in type 2 diabetes mellitus. Hebei Medical Journal 2011;33:2742-3.

18. He X, Zhang Y, Ruan Z, et al. The prevalence and related direct medical costs of chronic complications among patients with type 2 diabetes in China. Chin J Endocrinol Metab 2019;35:200-5.

19. Inzucchi SE, Bergenstal RM, Buse JB, et al. Management of hyperglycemia in type 2 diabetes, 2015: a patientcentered approach: update to a position statement of the American Diabetes Association and the European Association for the Study of Diabetes. Diabetes Care 2015;38:140-9.

20. Paul SK, Klein K, Thorsted BL, et al. Delay in treatment intensification increases the risks of cardiovascular events in patients with type 2 diabetes. Cardiovasc Diabetol 2015;14:100.

21. Chinese Diabetes Society; National Office for Primary Diabetes Care. National guidelines for the prevention and control of diabetes in primary care(2018). Zhonghua Nei Ke Za Zhi 2018;57:885-93.

22. Zhu D, Mu Y, Hong T, et al. Expert consensus on glucose-lowering pharmacotherapies in Chinese adults with type 2 diabetes and cardiovascular disease or chronic kidney disease. Chin J Diabetes Mellitus 2021;12:369-81. 
23. Wang $\mathrm{W}, \mathrm{Fu} \mathrm{C}, \mathrm{Pan} \mathrm{C}$, et al. How do type 2 diabetes mellitus-related chronic complications impact direct medical cost in four major cities of urban China? Value
Health 2009;12:923-9.

(English Language Editor: C Betlzar)

Cite this article as: Mao W, Qi X, Huang Y, Yang D, Wen C, Xiong X, Li Y, Zhao Z, Huang J, Luo K. China county-based demographics, clinical characteristics, treatment patterns, and health resource consumption analysis for diabetes. Ann Palliat Med 2021;10(7):8061-8071. doi: 10.21037/apm-21-1591 